\title{
Precious Metals-Exchange Rate Volatility Transmissions and Hedging Strategies*
}

\author{
Shawkat Hammoudeh \\ Lebow College of Business \\ Drexel University \\ Philadelphia, USA \\ Yuan Yuan \\ Lebow College of Business \\ Drexel University \\ Philadelphia, USA \\ Michael McAleer \\ Econometrics Institute \\ Erasmus School of Economics \\ Erasmus University Rotterdam \\ and \\ Tinbergen Institute \\ The Netherlands \\ and \\ Center for International Research on the Japanese Economy (CIRJE) \\ Faculty of Economics \\ University of Tokyo
}

Mark A. Thompson

Rawls College of Business

Texas Tech University

Lubbock, USA

EI2009-38

October 2009

*The authors thank Kyongwook Choi and other participants of the $84^{\text {th }}$ Western Economic Association International (WEAI) for helpful comments on an earlier version of this paper. The third author gratefully acknowledges the financial support of the Australian Research Council and National Science Council, Taiwan. 


\begin{abstract}
This study examines the conditional volatility and correlation dependency and interdependency for the four major precious metals (that is, gold, silver, platinum and palladium), while accounting for geopolitics within a multivariate system. The implications of the estimated results for portfolio designs and hedging strategies are also analyzed. The results for the four metals system show significant short-run and long-run dependencies and interdependencies to news and past volatility. These results have become more pervasive when the exchange rate and $F F R$ are included. Monetary policy also has a differential impact on the precious metals and the exchange rate volatilities. Finally, the applications of the results show the optimal weights in a two-asset portfolio and the hedging ratios for long positions.
\end{abstract}

Keywords: Multivariate, shocks, volatility, correlation, dependency, interdependency, precious metals, exchange rates, hedging.

JEL Classifications: C32, G10 


\section{Introduction}

The literature on commodities has concentrated on price co-movements and their roles in transmitting information about the macroeconomy. The research covers a wide scope of commodities including agricultural commodities, base metals, industrial metals and energy. The existing research on precious metals focuses mainly on gold and silver. Much of the past research on industrial metals is less generous when it comes to examining the volatility of returns of the precious metals. It mainly employs univariate models of the GARCH family to analyze volatility. Previous studies focused on own shock and volatility dependencies, while ignoring volatility and correlation interdependencies over time. Thus, they do not examine precious metals' shock and volatility cross effects. This could be a major shortcoming when one considers such applications as hedging, optimal portfolio diversification, inter-metal predictions and regulations. In this regard, we are interested in ascertaining to what extent precious metal interdependencies exist and the roles of hedging and diversification among them. In addition to policy makers, traders and portfolio managers, manufacturers would be interested in this information because the metals have important and diversified industrial uses in jewelry, medicine, and electronic and autocatalytic industries, as well as being investment assets.

The broad objective of this study is to examine conditional volatility and correlation dependency and interdependency for the four major precious metals: gold, silver, platinum and palladium, using multivariate GARCH models with alternative assumptions regarding the conditional means, conditional variances, conditional covariances and conditional correlations. We include the vector autoregressive, moving average GARCH (VARMA-GARCH) model and the dynamic conditional correlation (DCC) model. We use the DCC-GARCH model as a diagnostic test of the results of the 
VARMA-GARCH model. This method enables us to examine the conditional volatility and correlations cross effects with meaningful estimated parameters and less computational complications that characterize these models. A second objective is to examine the volatility feedback effects between the four precious metals and the US dollar/euro exchange. ${ }^{1}$ Almost all metals are sensitive to changes in the dollar exchange rates, particularly the dollar/euro rate, which is followed closely by currency and commodity practitioners and policy makers. We expect to have metals' volatility heighten when the dollar is weak and volatile because investors move to the safety of the dollar-priced precious metals. But we are also keen on knowing whether some precious metals volatility contributes to heightened volatility for the US dollar since both types of assets may be included in international foreign reserves. A third objective is to derive the implications of the estimated results on variances and covariances for effectuating optimal portfolio designs and hedging strategies.

This paper is organized as follows. After the introduction, we present a review of the literature on precious metal volatility in section 2 . Section 3 provides the data and their descriptive statistics. Section 4 illustrates the VARMA-GARCH and DCC-GARCH methodologies. The empirical results are discussed in section 5, while section 6 provides implications of the estimates of the models. Section 7 concludes.

\section{Review of the Literature}

Research on industrial commodities such as oil, copper and precious metals, among others, is much richer on explaining their co-movements and information transmissions than on illustrating their volatility and correlation dependency and

\footnotetext{
${ }^{1}$ In a classroom exercise on the historical correlations between the gold price and a group of dollar exchange rates and indices including dollar/euro, dollar/pound, dollar/yen, exchange rate index-broad and exchange rate index-major, the students found that the dollar/euro exchange rate has the highest correlation with the gold price over the daily period 1999-2009.
} 
interdependence. Moreover, research on volatility is more extensive for oil and energy than for precious metals. Within the precious metals, the research on volatility primarily employs univariate models of the GARCH family, addresses volatility dependency but not interdependency and focuses on one or two precious metals, neglecting other major ones such as platinum and palladium. McKenzie et al. (2001) explored the applicability of the univariate power ARCH volatility model (PARCH) to precious metals' futures contracts traded at the London's Metal Exchange (LME). They found that the asymmetric effects are not present and the model did not provide an adequate explanation of the data. Tully and Lucey (2007) used the univariate (asymmetric) power GARCH model (APGARCH) to examine the asymmetric volatility of gold. They concluded that the exchange rate is the main macroeconomic variable that influences the volatility of gold but few other macroeconomic variables had an impact. Batten and Lucey (2007) studied the volatility of gold futures contracts traded on the Chicago Board of Trade (CBOT) using intraday (high frequency) and interday data. They used the univariate GARCH model to examine the volatility properties of the futures returns and the alternative nonparametric Garman-Klass volatility range statistic (Garman and Klass, 1980) to provide further insights in intraday and interday volatility dynamics of gold. The results of both measures provided significant variations within and between consecutive time intervals. They also found slight correlations between volatility and volume.

In terms of nonlinearity and chaotic structure, Yang and Brorsen (1993) concluded that palladium, platinum, copper and gold futures have chaotic structures. In contrast, Adrangi and Chatrath (2002) found that the nonlinearity in palladium and platinum is inconsistent with chaotic behavior. They concluded that ARCH-type models with controls for seasonality and contractibility explained the nonlinear dependence in 
their data for palladium and platinum. They did not examine chaotic behavior of other precious metals.

In comparison with other commodities, Plourde and Watkins (1998) compared the volatility in the prices of nine non-oil commodities (including gold and silver) to volatility in oil prices. Utilizing several non-parametric and parametric tests, they found that the oil price tends to be more volatile than the prices of gold, silver, tin and wheat. They argued that the differences stand out more in the case of precious metals. Hammoudeh and Yuan (2008) included three univariate models of the GARCH family to investigate the volatility properties of two precious metals (gold and silver) and one base metal (copper). They found that, in the standard univariate GARCH model, gold and silver have almost the same volatility persistence, which is higher than that of the pro-cyclical copper. In the EGARCH model, they found that only copper has asymmetric leverage effect, and in the CGARCH model the transitory component of volatility converges to equilibrium faster for copper than for gold and silver. Using a rolling AR(1)-GARCH, Watkins and McAleer (2008) showed that the conditional volatility for two nonferrous metals, namely aluminum and copper, is time-varying over a long horizon.

In this paper, we include ARMA in the conditional mean equation to account for possible nonlinearity. Recent research has shown that ignoring this attribute may kill some of the dynamics of the relationships of the model. ${ }^{2}$ The recent literature has used different ways to deal with non linearity. Pertinent articles on this subject can be found in the book edited by Schaeffer (2008). Other articles include Westerhoff and Reltz (2005) and Kyrtsou and Labys (2007).

\footnotetext{
${ }^{2}$ We thank a referee for bringing this point to our attention and for providing pertinent references.
} 


\section{Data Description}

We utilized daily time series data (five working days per week) for the four precious commodity closing spot prices (gold, silver, platinum and palladium), federal funds rate (FFR) and U.S. dollar/euro exchange rate from January 4, 1999 to November 5, 2007. ${ }^{3}$ The exchange rate is the value of the US dollar to one euro, suggesting that a rise in the rate implies a devaluation of the dollar. The gold (GOLD), silver (SILV), palladium (PALL), and platinum (PLAT) are all traded at COMEX in New York and their price is measured in US dollars per troy ounce. ${ }^{4}$ The data for the daily federal funds rate $(F F R)$ and the US dollar/euro exchange rate $(E R)$ are obtained from the database of the Federal Reserve Bank of Saint Louis. All series are modeled in natural logarithms.

Since the precious metals, particularly gold, are sensitive to geopolitical crises, we included the geopolitical dummy variable, D03, to mark the beginning of the 2003 Iraq war. The historical paths of the six variables are graphed in Figure 1. We believe this geopolitical episode is more enduring and significant than the 9/11 event.

The descriptive statistics for the metals’ price levels in U.S. dollar and the returns are reported (in level form) in Tables 1-A and I-B, respectively. Unlike oil grades, the statistics show that the seemingly close precious metals do not belong to one great pool. Based on the coefficient of variation, gold price has the lowest historical volatility amongst all the precious metals prices, while palladium price has the highest because of its relatively small supply. The annual demand and production of gold are less than $10 \%$ of its above-ground supply. Its stock is a supply buffer against its fundamentals’ shocks. Gold price's low volatility is also consistent with the fact that gold has an important

\footnotetext{
${ }^{3}$ It is estimated that 80 percent of the world's platinum supply comes from South Africa, whereas Russia is the top producer of palladium. China seems to have overtaken South Africa as the No. 1 producer of gold. Mexico and Poland are the largest producers of silver.

${ }^{4}$ Price of silver is usually quoted in cents per troy ounce but we transformed it into dollars per troy ounce for consistency purposes.
} 
monetary component and is not used frequently in exchange market interventions. Gold is known to have notoriously extended bear markets, while silver price is more commodity-driven than gold as its monetary element was gradually phased out, but they are still closely related.

The statistics for the metals' returns generally follow those for their prices. Palladium return has the highest historical volatility followed by silver, as measured by standard deviation, while gold return has the lowest among the four metals. Silver outperforms gold when the market is up and does worse when the market is down. Traders know it is better to buy silver before gold when the market is booming, but to sell silver before gold when the market starts to head down. It is interesting to note that change in FFR is much more volatile than the four metals and the exchange rate's returns. In term of historical return means, platinum has the highest average return followed by silver, while gold and palladium have the lowest averages.

Contemporaneous correlations between metal price returns are shown in Table 2. The historical return correlation between platinum and palladium is positive and the highest among all precious metals, followed by the correlation between gold and silver returns. The saying goes "if you want to buy gold buy silver, and if you want to sell gold sell silver". The lowest correlation is between gold and palladium. The correlation between palladium return and those of gold and the other metals is positive. There is a noticeably strong correlation between gold and platinum. ${ }^{5}$ The change in the federal funds rate has a negative correlation with all the precious metals, as well as the exchange rate. The changes in prices of commodities and nominal interest rate are connected through changes in the dollar exchange rate and asset shifts from dollar-priced securities to commodities. The appreciation of the dollar exchange rate

\footnotetext{
${ }^{5}$ For information on the anecdotal evidence on the historical correlation between gold and platinum, see Hamilton (2000).
} 
(\$/euro) also is associated with higher short-term interest rates and lower commodity prices.

\section{Methodology}

Our objective is to upgrade the application of the univariate GARCH approach to a multivariate system with non linearity in the mean in order to examine the conditional volatility, correlation dependency, and interdependency for precious metals and US dollar/euro exchange rate in the presence of monetary policy by focusing on meaningful, interpretable parameters with minimal computational difficulties. Since BEKK did converge when exogenous variables are included, we employ the slightly more restrictive VARMA-GARCH model developed by Ling and McAleer (2003) to focus on interdependence of conditional variance and correlation among the precious metals and exchange rate, and the heavily more restrictive Multivariate Dynamic Conditional Correlation GARCH model (DCC-MGARCH) developed by Engle (2002) to focus on the evolution of conditional correlations over time and use it as a diagnostic test on the dynamics of the first model. ${ }^{6}$ These approaches should enable us to investigate conditional volatility interdependence, measure short- and long-run persistence in conditional correlations among the variables and derive the implications for optimal portfolio designs and hedging strategies using the two different types of the multivariate GARCH models.

\subsection{VARMA-MGARCH}

The precious metal commodities and the exchange rate in the VARMA-GARCH

\footnotetext{
${ }^{6}$ As mentioned above, we estimated the more general BEKK volatility model, but encountered convergence problems, less significant relationships and unreasonable parameter estimates. Therefore, we decided to use more heavily restricted models as it is well known that the BEKK model suffers from the archetypal "curse of dimensionality” (for further details, see Caporin and McAleer (2009)).
} 
system are indexed by $i$, and $n$ is total number of those commodities and the exchange rate when the latter is included in a variant model. The mean equation for the $\boldsymbol{i}^{\text {th }}$ precious metal/exchange rate in this system is $\operatorname{ARMA}(1,1)$ and given by:

$$
\begin{aligned}
& R_{i, t}=a_{i}+b_{i} R_{i, t-1}+\varepsilon_{i, t}+d_{i} \varepsilon_{i, t-1} \\
& \varepsilon_{i, t}=h_{i, t}^{1 / 2} \eta_{i, t}
\end{aligned}
$$

where $R_{i, t}$ is the return of the $i^{\text {th }}$ precious metal (or exchange rate) of the $n x l$ vector $R_{t}$ defined as the first logged difference and MA is the moving average. The MA process is included to account for nonlinearity in the mean equation. The innovation $\eta_{i, t}$ is i.i.d. random shock and $h_{i, t}$ is conditional variance of precious metal $i$ (or the exchange rate) at time $t$. Ling and McAleer (2003) proposed the specification of interdependent conditional variance:

$$
h_{i, t}=c_{i}+\sum_{j=1}^{n} \alpha_{i j} \varepsilon_{j, t-1}^{2}+\sum_{j=1}^{n} \beta_{i j} h_{j, t-1}
$$

as a generalization of Bollerslev (1986) univariate GARCH process, where $h_{i, t}$ is the conditional variance at time $t, h_{j, t-1}$ refers to own past variance for $\boldsymbol{i}=\boldsymbol{j}$ and past conditional variances of the other precious metals (and exchange rate) in the system for $\mathbf{i} \neq \mathbf{j}, \Sigma \alpha_{i j} \varepsilon_{j, t-1}^{2}$ is the short-run persistence or the ARCH effects of the past shocks, $\Sigma \beta_{i j} h_{j, t-1}$ is the long-run persistence or the GARCH effects of past volatilities. From (2), the conditional variance for the $i^{\text {th }}$ precious metal (or exchange rate) is impacted by past shocks and past conditional variances of all precious metals (or exchange rate), capturing interdependencies. Therefore, this specification allows for the cross-sectional dependency of volatilities among all precious metals (or exchange rate). The past shock and volatility of one asset are allowed to impact the future volatilities not only of itself but also of all the other assets.

The parameters of the VARMA-GARCH system defined above are obtained by 
using the maximum likelihood estimation (MLE) when the distribution of $\eta_{i, t}$ is standard normal and by quasi maximum likelihood estimation (QMLE) when the distribution is not standard normal. Ling and McAleer (2003) showed that the existence of the second moment is sufficient for consistency, while existence of the fourth moments is sufficient for the asymptotic normality of the QMLE. ${ }^{7}$ The i.i.d. of $\eta_{i, t}$ implies that conditional correlation matrix of $\varepsilon_{t}=\left[\varepsilon_{1, t}, \varepsilon_{2, t}, \cdots, \varepsilon_{n, t}\right]$ is constant over time. The constant correlation matrix is $\Gamma=E\left(\eta_{t} \eta_{t}{ }^{\prime}\right)$, where $\eta_{t}=\left[\eta_{1, t}, \eta_{2, t}, \cdots, \eta_{n, t}\right]^{\prime}$.

\subsection{DCC-MGARCH}

The assumption that the random shocks $\varepsilon_{t}=\left[\varepsilon_{1, t}, \varepsilon_{2, t}, \cdots, \varepsilon_{n, t}\right]$ ' have a constant correlation matrix may not be well supported in the commodity markets because of high uncertainty, structural changes, and geopolitical events. Moreover, some researchers prefer to use an MGARCH model of multiple equations that follows a univariate process and does not include any spillovers across variables. The results of this model can stand as diagnostic tests of those of VARMA-GARCH. Therefore, we apply Engle (2002) DCC-MGARCH to examine the time-varying correlations among commodities. Furthermore, in contrast to the specification of the interdependent conditional variance in equation (2) of VARMA-GARCH, the DCC-MGARCH model assumes that the conditional variance of each precious metal (or exchange rate) follows univariate GARCH process:

$$
h_{i, t}=c_{i}+\sum_{k=1}^{p} \alpha_{i, k} \varepsilon_{i, t-k}^{2}+\sum_{s=1}^{q} \beta_{i, s} h_{j, t-s}
$$

where $\Sigma \alpha_{i, k} \varepsilon_{i, t-k}^{2}$ is short-run persistence of precious metal (or exchange rate) $\boldsymbol{i}$ 's own

\footnotetext{
7 See Ling and McAleer (2003) for necessary and sufficient conditions in more details. Jeantheau (1998) proved consistency of the QMLE for the BEKK model of Engle and Kroner (1995).
} 
past shocks and $\Sigma \beta_{i, s} h_{i, t-s}$ is the long-run persistence of the GARCH effects of past volatilities. It is worth noting that in the equation (3) the conditional variances of precious metals (and exchange rate) are assumed to be independent from one another.

The estimation of dynamic conditional variance-covariance matrix of DCC-MGARCH entails two steps. First, the matrix $Q_{t}$ used to calculate the dynamic conditional correlation is assumed time-varying and governed by two parameters, $\theta_{l}$ and $\theta_{2}$ :

$$
Q_{t}=\left(1-\theta_{1}-\theta_{2}\right) Q_{0}+\theta_{1} \varepsilon_{t-1} \varepsilon_{t-1}^{\prime}+\theta_{2} Q_{t-1}
$$

where $Q_{0}$ is the unconditional correlation matrix of $\varepsilon_{t}$, which is a consistent estimator of the unconditional correlation matrix of commodities, $Q_{t}$ is a weighted average of a positive-definite and a positive-semidefinite matrix which is solely used to provide the dynamic correlation matrix, and $\theta_{1}$ and $\theta_{2}$ are parameters. $\theta_{1}$ represents the impact of past shocks on a current conditional correlation, and $\theta_{2}$ captures the impact of the past correlations. If both parameters $\theta_{1}$ and $\theta_{2}$ are statistically significant, then there is an indication that conditional correlations are not constant. The dynamic conditional correlation coefficients $\left(\rho_{i j}(t)\right)$ between commodities (or exchange rate) $\boldsymbol{i}$ and $\boldsymbol{j}$ are calculated by:

$$
\rho_{i j}(t)=\frac{Q_{i j}(t)}{\sqrt{Q_{i i}(t) Q_{j j}(t)}}
$$

Second, the sequence of dynamic conditional covariance matrix is then computed by $\rho_{i j}(t)$ and the estimated univariate conditional variances:

$$
H_{i j}(t)=\rho_{i j}(t) \sqrt{H_{i i}(t) H_{j j}(t)}
$$




$$
H(t)=\left[\begin{array}{cccc}
h_{11, t} & h_{12, t} & \cdots & h_{n 1, t} \\
h_{21, t} & \ddots & \ddots & h_{2 n, t} \\
\vdots & \ddots & \ddots & \vdots \\
h_{n 1, t} & h_{n 2, t} & \cdots & h_{n n, t}
\end{array}\right]
$$

where $h_{i i, t}=h_{i, t}$ is for the convenience of notation, which is estimated based on the univariate GARCH process as showed in equation (3). The elements $h_{i i, t}$ and $h_{i j, t}$ are the estimated conditional variance and conditional covariance, respectively, at time $t$ and $h_{i j, t}=h_{j i, t}$.

\section{Empirical Results}

We present the estimates of different VARMA-GARCH models with varying degrees of parameter restrictions and included variables in order to capture appropriate nonlinearity and dynamics. ${ }^{8}$ These are: VARMA-GARCH Model I for the four precious metals in presence of geopolitics, VARMA-GARCH Model II for three precious metals and the exchange rate in presence of monetary policy and geopolitics, and two more restricted models, VARMA-DCC Model III for the four precious metals and VARMA-DCC Model IV for the three precious metals and the exchange rate in the presence of monetary policy. ${ }^{9}$ The results of the two DCC models (Models III and IV) are meant to stand as a diagnostic check on models I and II since a constant conditional correlation matrix may not be well supported in commodity markets. ${ }^{10}$ All models include the geopolitical dummy D03 to capture the impact of the ongoing 2003 Iraq war.

\footnotetext{
${ }^{8}$ The results for the more general BEKK version for models I and II are not provided because this GARCH version did not converge when exogenous variables are included. When those variables are excluded, the results exhibit less dynamics than for the VARMA-GARCH models.

${ }^{9}$ RATS 6 was used. The estimation algorithm is discussed in Ling and McAleer (2003).

10 The BEKK frequently does not converge when there are more than four assets, so its over-parameterization (otherwise known as "the curse of dimensionality") is a serious computational problem. See McAleer (2005) for further discussion of this issue.
} 
The volatility proxies for the exchange rate $h_{\mathrm{er}}(\mathrm{t}-1)$ and federal funds rate (DLFFRSQ(-1)) defined as a percentage change of the lagged sums of the squared deviation from their respective means, are included in the variance equations. Model II does not include palladium because the system model does not converge with more than four endogenous variables and one lagged exogenous policy variable. Moreover, this metal has very small supply relative to gold and silver and is the least known and traded of the four metals. ${ }^{11}$

We estimate these four models with and without nonlinearity in the mean equations. The results show unequivocally that the models with nonlinear means have more relational dynamics than those without. We only report results for the nonlinear case. This is consistent with the findings of the recent literature.

\subsection{Model I(VATMA-GARCH): The Four Precious Metals}

The estimates of the VARMA-GARCH for the four precious metals in Model I are provided in Table 3. The ARCH $(\alpha)$ and GARCH $(\beta)$, own past shocks and volatility effects respectively, are significant for all the precious metals. The degree of persistence is $0.736,0.978,0.976$ and 0.909 for gold, silver, platinum and palladium, respectively. This means the convergence to long-run equilibrium after shocks is the slowest for gold and the fastest for silver, with silver and platinum exhibiting similar persistence, which means that investors can wait more on silver than on the other three metals to converge.

\section{Own shock volatility}

The degree of own news sensitivity or short-run persistence (ARCH effect) varies across those metals, with palladium and gold showing the most news sensitivity while silver displaying the least (Table 3). Specifically, palladium and gold have the highest $\alpha$

\footnotetext{
${ }^{11}$ We thank a referee for bringing this point to our attention.
} 
or (news) shock dependency in the short run, amounting to 0.152 and 0.145 , respectively, while silver's sensitivity is 0.006 . Palladium has a small supply, is particularly active during crisis times, and usually exhibits more volatility at a later stage of the crisis cycle. Gold $(\alpha=0.145)$ is very sensitive to news, likely because it is the most watched metal by traders and policy makers. The exotic metal, platinum, has the lowest shock sensitivity $(\alpha=0.080)$, perhaps because it is very expensive. This news-oriented result thus separates the four precious metals into two groups: the high news-sensitivity group that includes gold and palladium, and the really low newssensitivity group that encompasses silver and platinum. Traders who favor more news-sensitive precious metals should focus their eyes on the first group, while those who disfavor volatility should focus on the second group.

\section{Own volatility dependency}

As in the case of shock dependency, all four precious metals in this model show significant $\beta$ sensitivity to own past volatility in the long run (Table 3). However, the magnitude of the past volatility sensitivity is much greater than that of the past shock sensitivity, while the disparity among the metals for the former is much smaller than in the latter. This result implies that the precious metals are generally more influenced by common fundamental factors (e.g., macroeconomic factors) than by shocks (e.g., fires in mines or strikes). In contrast to the shock sensitivity, volatility sensitivity places silver and platinum (0.972 and 0.895$)$ in the high volatility sensitivity group, while gold and palladium (0.590 and 0.758$)$ in the relatively low volatility group.

As shown above, gold $(\beta=0.590)$ is relatively less sensitive to macroeconomic variables in the long run because of its vast above-ground supply that acts as a buffer against changes in annual demand and production in the long run. It is also known to have extended bear markets. On the other hand, silver $(\beta=0.972)$ is more 
commodity-driven than gold, and thus seems to be more influenced by long-run economic factors that affect the business cycles than gold. Platinum $(\beta=0.895)$, the white metal, which is mostly used as an industrial commodity is sided more with silver than with the yellow metal when the long-run own volatility sensitivity is concerned. This result shows some distancing between gold and platinum than is known in the marketplace. ${ }^{12}$ This relative separation had become more evident during the recent commodity boom. Meanwhile, the grey dull metal, palladium $(\beta=0.758)$, shows a long run conditional volatility that is less than platinum but considerably higher than gold. In sum, when gold is added to a diversified portfolio, it is likely to raise volatility in the short run but does less so in the long run. This is due to its short run sensitivity to news and its long run above-ground supply buffer that smoothes out daily and annual fluctuations. However, silver platinum, and palladium add to long-run volatility in this respect.

\section{Short-run shock interdependency}

The results also show that spillovers among the four metals are significant, except for the cross-shock effects emanating from the gold and platinum to palladium (Table 3). Still, the cross shock effects among all the four metals are limited as is the case with the own shock effects, lowering the interaction and influence of common global shocks on the four metals. This implies that the precious metals do not belong to "one great pool" in the short run, dissimilar to the crude oil case, which also has many different oil grades but all are commonly affected by shocks (e.g., accidents or fire incidents in oil fields). It is interesting to note that the shock impact from palladium on platinum is significant but negative (-0.031). This finding suggests that shocks to palladium are likely to cool off

\footnotetext{
${ }^{12}$ See Hamilton (2000) for a closer relationship between gold and platinum
} 
platinum volatility, possibly because they are substitutes in industrial production.

In terms of specific cross shock effects for the individual metal, gold is affected positively by previous inter-shocks from silver (0.038) and, to a lesser extent, from palladium (0.026) in the short run. This shock spillover reflects gold's high sensitivity to its own news, and the positive (historical) contemporaneous correlations between the returns of gold and silver as is provided in Table 2. In addition to figuring high in commodity investment portfolios as safe havens, gold and silver metals are also used in the jewelry industry. The reason for the cross shock impact of palladium on gold is not clear.

In contrast to gold, silver is cross-shock influenced by past shocks from all the metals (-0.038 from gold, -0.008 from platinum, and -0.049 from palladium) in addition to its own (0.006). Thus, silver shares common shocks with the other metals. Since all the cross shock effects are negative, there is likely a reduction in a silver conditional volatility coming from the other metals except from itself when combined in a diversified portfolio. This result suggests that cross-metal news sensitivity may offset more own-news sensitivity effects within a diversified portfolio. Platinum and palladium are positively affected by cross shocks from the other metals except from each other.

\section{Long run volatility interdependency}

In contrast to the short-run cross shock effects and without exception, the long-run impacts of cross past volatility are significant for all the metals. The cross volatility impacts are, however, small relative to its own impact. The exception is the cross effect between gold and palladium, which is estimated at 0.528 (Table 3). Palladium displays volatility late in a crisis, but the result suggests that palladium's past volatility feeds into gold volatility. 
Gold is consistently the most sensitive to long-run volatility interdependence with respect to all other metals (-0.05 from silver, 0.175 from platinum, and 0.528 from palladium). Based on anecdotal correlation evidence, Hamilton (2000) showed that platinum is a leading indicator of gold. However, our conditional results show stronger influence coming from palladium in the long run.

Gold also has the strongest cross volatility spillover impact on the other metals. Factors that affect gold seem to more notably impact the other metals. This result should not be surprising as the shiny metal is used in jewelry, industry, and as a safe haven investment and part of international reserve, while the other metals are used substantially in industrial purposes such as electronics and auto-related industries. The strong interdependence with gold is probably due to the yellow metal being the big brother with vast above-ground supply, and also being the most watched precious metal by traders and policy makers. In a practitioner's words "Silver investors and speculators all watch the gold price...it is the primary ingredient coloring their sentiment. So when gold is looking strong, they flood into silver and bid it up rapidly. And when gold weakens, many are quick to exit silver."13 We should also note that during the recent crisis, gold was driven down to a 14-month low but silver plummeted to a 34-month low. It could also be due to the close relationship between gold and the dollar.

Silver is the third most (interdependently volatility) sensitive after gold and palladium, affected positively by gold and palladium (0.190 and 0.021, respectively) and negatively platinum (-0.081). Finally, platinum and palladium are affected by long-run volatility spillovers from all the other metals and from each other because both shared common uses in autocatalysis, jewelry, and electronics.

There is only one pair of metals that has a two-way negative conditional volatility

\footnotetext{
${ }^{13}$ See Hamilton (2009). He calls silver “gold’s lapdog.”
} 
interdependency in the long run. Silver and platinum's past volatilities offset each other's current volatility, implying that they are negatively affected by common fundamental factors. However, this impact is miniscule compared to that of own past volatilities, suggesting that silver and platinum may not be included in a portfolio that aims at reducing volatility in the long run, despite silver's better behavior in this regard.

\section{Geopolitics}

When it comes to sensitivity of precious metals to geopolitical events, the 2003 Iraq war slightly elevated the mean returns of both gold and silver as a result of flight to safety (Table 3). ${ }^{14}$ The results, however, do not show that this war generated the same flight to safety across platinum and palladium. Investors who are interested in average returns demand risk premium from holding gold and silver, while those who favor platinum and palladium do not.

When it comes to conditional volatility, silver responded positively to this war, while platinum and palladium responded negatively in the long run. This implies that investors and traders of these metals hedge differently against volatility caused by geopolitics during such events.

\section{Constant conditional correlations (CCC)}

As expected, all the CCCs between the four precious metal returns are positive

(Table 3). The conditional correlations between the precious metal returns are below 0.50 reflecting varying news sensitivity and economic uses. All the estimates show that the highest CCC is between platinum and palladium (0.48). These metals are used in the same industries and the former plays catch up to the latter. The second highest CCC is between gold and silver (0.42), which is not surprising considering that these two metals

\footnotetext{
${ }^{14}$ When the September 11th dummy is used, similar results are obtained for volatility.
} 
are the most widely traded among the precious metals and both are used in jewelry and as an investment vehicle. The lowest is between the most traded gold and the least traded palladium. All these conditional correlations are in line with the contemporaneous correlations provided in Table 2.

\subsection{Model II (Expanded VARMA-GARCH): Precious Metals and Exchange Rate}

This expanded volatility system includes the dollar/euro exchange rate, three precious metals as endogenous variables, the federal funds rate as a policy variable and the geopolitical dummy. Palladium is excluded for three reasons. First, it is characterized by a very small annual production, compared to gold and silver. Second, it is not widely traded on world commodity trading centers and considered a "junior" precious metal. Third, the VARMA-GARCH (as well as BEKK) did not converge when palladium was added to gold, silver, platinum and exchange rate in the presence of $F F R$ and the geopolitical variable.

The ARCH $(\alpha)$ and GARCH ( $\beta$ ) effects for this model are significant for all the metals as is the case in the previous model (see Table 4). The degrees of persistence are: 0.695, 0.975, 0.949 and about 1.005 for gold, ${ }^{15}$ silver, platinum and exchange rate, respectively, with GARCH effect dominating the ARCH effect, implying that conditional volatility is predictable from past data. The numbers are comparable with the (purely) commodity model, Model I, also implying tardiness in convergence to the long-run equilibrium. We should also mention that the volatility persistence for gold has increased in this model relative to the previous model because gold is highly sensitive to changes in exchange rate and monetary policy. Another noticeable difference is that many own and cross-past shocks and volatility spillover effects have lessened slightly in

\footnotetext{
${ }^{15}$ In a multivariate GARCH model, coefficients are not restricted to the interval $(-1,1)$.
} 
Model II relative to Model I as some of these volatilities shifted from being metals volatility to metals-currency rate volatility.

The long-run fluctuations in the exchange rate in the form of a falling dollar and the presence of monetary policy increases the cross currency/metal volatilities, attesting the safe haven phenomenon is alive and well in this model (Table 4). Gold and platinum are the highest recipients of this cross exchange rate volatility followed by silver. All in all, this implies that there are economic fundamental factors related to the exchange rate volatility that escalate the precious metals volatilities.

Interestingly, there are also strong volatility spillovers from precious metals to the exchange rate but with differential impacts. Gold has the strongest cross reversal impact and silver and platinum have lower but similar effects. Precious metals can be considered as resource currencies. Gold's past volatility escalates the exchange rate volatility. The yellow metal and US dollars are integral part of international foreign reserves for many central banks and gold is the first safe haven for the dollar.

The findings also suggest that the volatility of the federal funds rate has significant impacts, though differential, on the three precious metals and the exchange rate. Monetary policy makers consider gold price a harbinger of inflation. The monetary authority can also dampen the volatility of the dollar exchange rate by changing the federal funds rate, but doing so may lead to an escalation of the volatility of the major precious metals markets.

In this system, the impact of the 2003 Iraq war on both metal returns and volatility is significant. It elevates the average returns of all metals and depreciates the US dollar relative to the euro because of the flight to safety from dollar assets to hard assets. Silver's average return is affected the most, while platinum return is affected the least. The war also increases the volatility of all three metals as well as the dollar volatility. It 
affects the gold volatility the most and that of platinum the least. Contrary to the previous the model, it is possible that the interaction of the geopolitical variable and the exchange rate in this model helps elevate the impact of geopolitics in this model.

There is no change in the positive conditional correlations among the precious metals in the expanded system from the previous one. In sum, accounting for the exchange rate as an endogenous variable and $F F R$ as a monetary policy variable in the system reduces the metals' volatilities because the metal-to-metal volatilities are moderated by the metals-to-exchange rate volatilities despite the strong volatility spillovers from the metals to the exchange rate. The policy implication of this finding suggests that traders, producers, and policy makers should take this moderation effect into account when making decisions. It also points to the significance of a freely moving dollar exchange rate in moderating metal volatilities.

\subsection{Model III (VARMA-DCC): The Four Precious Metals}

The estimates of this VARMA-DCC model for the four precious metals are provided in Table 5. These estimates are significant and mirror, to a large extent, the estimates of Model I, underpinning the robustness of the results. The ARCH $(\alpha)$ and GARCH $(\beta)$, own past (unexpected) shocks and volatility effects, respectively, are significant for all the precious metals, including platinum's own shock and its spillover shock to gold. These are the only shocks that are not significant in Model I. The degrees of persistence in this model are higher for some metals, particularly gold, than in Model I. They are: $0.913,0.980,0.978$ and 0.975 for gold, silver, platinum and palladium, respectively.

The news or shock effects in the (purely) metals model are comparable to those of Model I, except for silver despite the elimination of cross shock effects in this model

(Table 5). The estimate of the silver's own shock effect in this model is much greater 
than in Model I and close to that of platinum. The effects of past volatility are mixed compared to their counterparts in Model I. This implies that the restriction of cross-over volatility effect can have measured mixed effects on own volatility of the precious metals.

Figure 2 shows the evolution of conditional correlations between pairs of precious metals over time for Model III (VARMA-DCC). ${ }^{16}$ The range of this evolution is between 0.1 and 0.6, which justifies the use of the VARMA-GARCH model in examining the volatility transmissions between those commodities. These different correlations echo different advantages and varying roles played by these commodities over time.

Our estimates for the DCC model also mirror those that are found in the literature, namely that the lagged conditional correlation matrix has the coefficient $\theta_{2}$ close to unity. There are no long-run dynamic conditional correlations as the effect of shocks, or news, is zero. This result may also justify using the VARMA-GARCH models.

\subsection{Model IV (Expanded VARMA-DCC): Precious Metals and Exchange Rate}

Similar to the expanded model II (VARMA-GARCH), this expanded DCC volatility system includes the dollar/euro exchange rate, three precious metals as endogenous variables, the federal funds rate as a policy variable and the geopolitical dummy variable. The results show that all own shock and volatility effects are significant. The shock effects in this model are almost identical to those of VARMA-DCC in Model III, while the volatility effects are lower for silver and platinum but higher for gold (Table 6). We conclude that restricting the shock and volatility spillovers does not affect the own shock effects much, but it does have mixed

\footnotetext{
${ }^{16}$ The corresponding graphs for Model IV are very similar to the graphs in Figure 2 and, thus, are available upon request.
} 
effects on the own volatility spillovers.

\section{Implications for Portfolio Designs and Hedging Strategies}

We provide two examples for constructing optimal portfolio designs and hedging strategies using our estimates of Model I (VARMA-GARCH) for the four precious metals and the geopolitical dummy variable and Model II (VARMA-GARCH) for the three precious metals and exchange rate in presence of monetary policy and geopolitics.

The first example follows Kroner and Ng (1998) by considering a portfolio that minimizes risk without lowering the expected returns. In this case, the portfolio weight of two assets holdings is given by:

$$
w_{12, t}=\frac{h_{22, t}-h_{12, t}}{h_{11, t}-2 h_{12, t}+h_{22, t}}
$$

and

$$
w_{12, t}=\left\{\begin{array}{lll}
0, & \text { if } & w_{12, t}<0 \\
w_{12, t}, & \text { if } & 0 \leq w_{12, t} \leq 1 \\
1, & \text { if } & w_{12, t}>1
\end{array}\right.
$$

where $w_{12, t}$ is the weight of the first precious metal in one dollar portfolio of two precious metals at time $t, h_{12, t}$ is the conditional covariance between metals 1 and 2 and $h_{22, t}$ is the conditional variance of the second metal. Obviously, the weight of the second metal in the one dollar portfolio is $1-w_{12, t}$.

The average values of $w_{12, t}$ based on our Model I (VARMA-GARCH) estimates are reported in the first column of Table 7. For instance, the average value of $w_{12, t}$ of a portfolio comprising gold and silver is 0.81 in favor of the yellow metal. This suggests that the optimal holding of gold in one dollar of gold/silver portfolio be 81 cents and 19 cents for silver. These optimal portfolio weights suggest that investors should have more gold than silver and other precious metals in their portfolios to minimize risk 
without lowering the expected return. This is not surprising, given that the CCC coefficient between these two metals is the second highest. Investors should also have more platinum than silver (60\% to $40 \%$ ) in their portfolios. These two precious metals are not (relatively) highly correlated. When it comes to the two platinum and palladium, the optimal portfolio should be $83 \%$ to $17 \%$ in favor of the exotic metal over the dull one, because they have the highest correlation among the four metals.

All the optimal weight results are confirmed by the estimates of the more restricted model, Model III (VARAM-DCC), which gives very similar results. The DCC estimates are not reported here but are available on request.

We now follow the example given in Kroner and Sultan (1993) regarding riskminimizing hedge ratios and apply it to our precious metals. In order to minimize risk, a long (buy) position of one dollar taken in one precious metal should be hedged by a short (sell) position of $\$ \beta_{t}$ in another precious metal at time $t$. The rule to have an effective hedge is to have an inexpensive hedge. The $\beta_{t}$ is given by:

$$
\beta_{t}=\frac{h_{12, t}}{h_{22, t}}
$$

where $\beta_{t}$ is the risk-minimizing hedge ratio for two precious metals, $h_{12, t}$ is the conditional covariance between metals 1 and 2 and $h_{22, t}$ is the conditional variance of the second metal.

The second column of Table 7 of Model I (VARMA-GARCH) reports the average values of $\beta_{t}$. The values for hedge ratios for the four precious metals are smaller than those for equity markets (Hassan and Farooq, 2007). By following this hedging strategy, one dollar long (buy) in gold for example should be shorted by about 19 cents of silver. The results show that it is more (hedging) effective to hedge long (buy) gold positions by shorting (selling) palladium (than by silver and platinum). Gold and palladium have 
the lowest CCC among all the pairs. The most (least) effective strategy to hedge silver is also to short palladium (platinum). The least effective hedging among all the precious metals is hedging long (buy) platinum position using (selling) palladium. Obviously, the CCC between the two cousins (platinum and palladium) is the highest among any pairs of the precious metals. This case implies hedging is more effective when a long (buy) position in one precious metal is hedged with a short (sell) position in another precious metal that is not closely related to the first one.

These values for $\beta_{t}$ are also similar to those obtained from Model III (DCC for the four metals). These results will not be repeated in this paper and are available on request.

The optimal portfolio weights and hedging ratios for Model II (VARMA-GARCH) for the three precious metals and exchange rate in presence of monetary policy and geopolitics are provided in Table 8. The optimal weights for the optimal two-asset portfolios: (gold/silver), (gold/platinum), and (silver/platinum) are the same as in Table 7. The interesting new optimal weights are for the holdings of a precious metal and the U.S. dollar exchange rate representing the value of the dollar. The portfolio gold/dollar has the highest weight for gold among the three precious metals included in Model I, while the silver/dollar portfolio has the lowest. It seems that gold commands the highest weight against the U.S. dollar because it is considered the safest haven against fluctuations in the dollar. Silver does not seem provide enough diversification benefits like gold and platinum.

The same are also obtained from Model IV (VARMA-DCC) for the three metals and the exchange rate in presence of monetary policy and geopolitics.

\section{Conclusions}


This paper investigates conditional own and spillover volatilities and correlations for gold, silver, platinum and palladium and also with the exchange rate in simultaneous multivariate settings using the VARMA-GARCH and the more restrictive VARMA-DCC models. The results of these models are used to calculate the optimal two-asset portfolio weights and the hedging ratios. The models have varying-levels of restrictions relative to the BEKK model, which did not converge when exogenous variables were included. Even when the exogenous variables were removed, BEKK gave less reasonable estimates. ${ }^{17}$ On the other hand, VARMA-GARCH and VARMA-DCC gave more interpretable parameters and have less computational and convergence complications.

Thus, our broad objective in this study is to examine the volatility and correlation interdependence among those seemingly close metals and with the US dollar/euro exchange rate in the presence of monetary policy and geopolitcs. Our consequential objective is to apply the results to derive optimal portfolio weights and hedging ratios.

The results show that almost all the precious metals are moderately sensitive to own news and weakly responsive to news spilled over from other metals in the short run. This underscores the importance of hedging in the short run, but it also shows that hedging precious metals against each other has its limitation.

There is however strong volatility sensitivity to own past shocks in the long run, with the strongest sensitivity bestowed on silver and the weakest on gold. The saying goes "if you like gold, buy silver and if you want to sell gold sell silver." The spillover volatilities are also stronger than the spillover shocks or news, which implies that these volatilities are predictable. The CCC matrix shows that gold and silver have the highest conditional correlations (0.42) among any pairs of the precious metals after platinum

\footnotetext{
${ }^{17}$ For more information, see Caporin and McAleer (2009). "Do we really need both BEKK and DCC? A
} tale of two covariance models,” available at SSRN: $\underline{\text { http://ssrn.com/abstract=1338190 }}$ 
and palladium (0.48).

Examining the volatility sensitivity of precious metals to the exchange rate volatility in the presence of monetary policy in Model II, the estimates show this sensitivity is strong, particularly for silver. The results reflect the fact that gold is the safest haven in the flight from the dollar to the safety of the precious metals. There are also weak reverse volatility spillovers from the precious metals to the exchange rate.

The above results reflect on the strategies that aim at designing optimal portfolio holdings and effective hedging. Among the pairs of metals that are highly correlated like gold and silver, the optimal two-asset holding tilts strongly for one asset at the expense of the other ones. The results show we do not have well balanced two-asset portfolios for the precious metals. These findings also manifest themselves in the size of the hedging ratios between pairs of metals and metals/exchange rate. These results point out to the specificity of hedging gold against exchange rate risk. 
Table 1-A: Descriptive Statistics for Levels

\begin{tabular}{lcccccc}
\hline & $G O L D$ & $P A L L$ & $P L A T$ & $S I L V$ & $E R$ & $F F R$ \\
\hline Mean & 399.466 & 366.381 & 752.290 & 6.873 & 1.114 & 3.594 \\
Std. Dev. & 138.198 & 186.035 & 285.904 & 3.032 & 0.163 & 1.863 \\
C.V. & 0.346 & 0.508 & 0.380 & 0.441 & 0.147 & 0.518 \\
Skewness & 0.952 & 1.605 & 0.541 & 1.243 & -0.080 & -0.079 \\
Kurtosis & 2.678 & 5.332 & 2.242 & 3.096 & 1.704 & 1.505 \\
J.B. & 358.483 & 1511.853 & 167.761 & 595.090 & 163.824 & 217.154 \\
Probability & $<0.01$ & $<0.01$ & $<0.01$ & $<0.01$ & $<0.01$ & $<0.01$ \\
Obs. & 2306 & 2306 & 2306 & 2306 & 2306 & 2306 \\
\hline
\end{tabular}

Notes: In this panel, we provide the data statistics in levels to place the prices of the absolute US dollar values in perspective. GOLD is gold price, $P A L L$ is palladium price, $P L A T$ is platinum price, $S L V R$ is silver price, $F F R$ is federal funds rate, $E R$ is US dollar/euro exchange rate and C.V. is the coefficient of variation. 
Table 1-B: Descriptive Statistics for Returns

\begin{tabular}{lcccccc}
\hline & $D L G O L D$ & $D L P A L L$ & $D L P L A T$ & $D L S I L V$ & $D L E R$ & $D L F F R$ \\
\hline Mean & $4.5 \mathrm{E}-04$ & $3.7 \mathrm{E}-05$ & $6.0 \mathrm{E}-04$ & $4.7 \mathrm{E}-04$ & $8.8 \mathrm{E}-05$ & $-3.3 \mathrm{E}-04$ \\
Std. Dev. & 0.010 & 0.021 & 0.013 & 0.016 & 0.006 & 0.114 \\
C.V. & $2.22 \mathrm{E}+01$ & $5.68 \mathrm{E}+02$ & $2.17 \mathrm{E}+01$ & $3.40 \mathrm{E}+01$ & $6.82 \mathrm{E}+01$ & $-3.45 \mathrm{E}+02$ \\
Skewness & 0.116 & -0.261 & -0.262 & -1.577 & 0.009 & 0.213 \\
Kurtosis & 8.919 & 6.846 & 7.856 & 19.428 & 4.032 & 38.825 \\
Jarque-Bera & 3370.049 & 1446.515 & 2290.749 & 26875.660 & 102.344 & 123282.600 \\
Probability & 0 & 0 & 0 & 0 & 0 & 0 \\
Observations & 2305 & 2305 & 2305 & 2305 & 2305 & 2305 \\
\hline
\end{tabular}

Notes: $D L G O L D$ is gold return, $D L P A L L$ is palladium return, $D L P L A T$ is platinum return, $D L S L V R$ is silver return, $D L F F R$ is percentage change in federal funds rate and $D L E R$ is US dollar/euro exchange rate return. All are logged first differences. 
Table 2: Contemporaneous Correlation Matrix between Returns

\begin{tabular}{lcccccc}
\hline \multicolumn{1}{c}{ Returns } & GOLD & PALL & PLAT & SILV & ER & FFR \\
\hline GOLD & 1.00 & & & & & \\
PALL & 0.26 & 1.00 & & & & \\
PLAT & 0.33 & $\mathbf{0 . 4 7}$ & 1.00 & & & \\
SILV & $\mathbf{0 . 3 7}$ & 0.32 & 0.31 & 1.00 & & \\
ER & $\mathbf{0 . 3 0}$ & 0.15 & 0.16 & 0.26 & 1.00 & \\
$F F R$ & -0.01 & -0.02 & -0.01 & -0.05 & -0.02 & 1.00 \\
\hline
\end{tabular}


Table 3: Model I-Estimates of VARMA-GARCH for the Four Precious Metals

\begin{tabular}{|c|c|c|c|c|c|c|c|c|}
\hline & \multicolumn{2}{|l|}{ Gold } & \multicolumn{2}{|l|}{ Silver } & \multicolumn{2}{|c|}{ Platinum } & \multicolumn{2}{|l|}{ Palladium } \\
\hline & \multicolumn{8}{|c|}{ Mean Equation } \\
\hline$C$ & -0.0001 & \multirow[b]{2}{*}{$\mathrm{a}$} & -0.0004 & b & 0.0002 & \multirow[b]{2}{*}{$\mathrm{b}$} & \multicolumn{2}{|l|}{$-4.8 \mathrm{E}-05$} \\
\hline$A R(1)$ & 0.5422 & & -0.1955 & $a$ & -0.0384 & & \multicolumn{2}{|l|}{0.0253} \\
\hline$M A(1)$ & -0.5029 & $\mathrm{a}$ & 0.0448 & b & -0.0086 & & 0.0057 & \\
\hline D03 & 0.0003 & $\mathrm{a}$ & 0.0011 & $\mathrm{a}$ & 0.0002 & & \multicolumn{2}{|l|}{$-3.0 \mathrm{E}-05$} \\
\hline \multicolumn{9}{|c|}{ Variance Equation } \\
\hline C & 4.0E-06 & $\mathrm{a}$ & $1.0 \mathrm{E}-06$ & $\bar{a}$ & $4.0 \mathrm{E}-06$ & $\bar{a}$ & 1.7E-05 & a \\
\hline$\varepsilon_{\text {gold }}^{2}(\mathrm{t}-1)$ & 0.1452 & \multirow[b]{2}{*}{$\mathrm{a}$} & 0.0353 & a & -0.0052 & & 0.0260 & $\mathrm{~b}$ \\
\hline$\varepsilon_{\text {silver }}^{2}(\mathrm{t}-1)$ & -0.0380 & & 0.0062 & $\mathrm{a}$ & -0.0079 & $\mathrm{a}$ & -0.0496 & $\mathrm{a}$ \\
\hline$\varepsilon_{\text {platinum }}^{2}(\mathrm{t}-1)$ & 0.0275 & a & 0.0137 & $\mathrm{a}$ & 0.0801 & $\mathrm{a}$ & -0.0305 & a \\
\hline$\varepsilon_{\text {palladium }}^{2}(\mathrm{t}-1)$ & 0.0016 & \multirow[b]{2}{*}{$\mathrm{a}$} & 0.0023 & $\mathrm{a}$ & -0.0010 & \multirow[b]{2}{*}{$\mathrm{a}$} & 0.1516 & $\mathrm{a}$ \\
\hline$h_{\text {gold }}(\mathrm{t}-1)$ & 0.5904 & & -0.0499 & $\mathrm{a}$ & 0.1745 & & 0.5284 & a \\
\hline$h_{\text {silver }}(\mathrm{t}-1)$ & 0.1899 & \multirow{2}{*}{$\begin{array}{l}\mathrm{a} \\
\mathrm{a}\end{array}$} & 0.9717 & $\mathrm{a}$ & -0.0806 & a & 0.0212 & a \\
\hline$h_{\text {platinum }}(\mathrm{t}-1)$ & 0.1054 & & -0.0707 & $\mathrm{a}$ & 0.8954 & a & 0.0952 & a \\
\hline$h_{\text {palladium }}(\mathrm{t}-1)$ & 0.5284 & a & 0.0212 & a & 0.0952 & $\mathrm{a}$ & 0.7578 & a \\
\hline$\alpha+\beta$ & 0.736 & & 0.978 & & 0.976 & & 0.909 & \\
\hline D03 & $-3.0 \mathrm{E}-08$ & & $1.0 \mathrm{E}-06$ & $\mathrm{a}$ & $-2.0 \mathrm{E}-06$ & a & $-1.3 \mathrm{E}-05$ & a \\
\hline
\end{tabular}

Constant Correlation Matrix

\begin{tabular}{|c|c|c|c|c|c|c|c|c|}
\hline Gold & 1.00 & & & & & & & \\
\hline Silver & 0.42 & $\mathrm{a}$ & 1.00 & & & & & \\
\hline Platinum & 0.38 & $\mathrm{a}$ & 0.35 & $\mathrm{a}$ & 1.00 & & & \\
\hline Palladium & 0.27 & a & 0.30 & a & 0.48 & $\mathrm{a}$ & 1.00 & \\
\hline Log Likelihood & 27697.29 & & & & & & & \\
\hline AIC & -23.98 & & & & & & & \\
\hline $\begin{array}{l}\text { J.B. Stat } \\
\text { Breusch-Godfrey }\end{array}$ & 3344.6 & $\mathrm{a}$ & 23296.2 & a & 2437.8 & a & 1432 & a \\
\hline $\begin{array}{l}\text { LM Stat } \\
\text { Durbin-Watson }\end{array}$ & 3.89 & $\mathrm{~b}$ & 36.98 & $\mathrm{a}$ & 1.57 & & 6.23 & $\mathrm{~b}$ \\
\hline Stat & 2.08 & & 1.75 & & 1.95 & & 1.90 & \\
\hline \#Obs. & 2304 & & & & & & & \\
\hline
\end{tabular}

Notes: This model includes the four precious metals -gold, silver, platinum and palladium- as the endogenous variables and $D 03$ as the exogenous variable. ${ }^{a} a n d^{b}$ denote rejection of the hypothesis at the $1 \%$ and $5 \%$ level, respectively. $\varepsilon_{j}^{2}(t-1)$ represents the past shock (news) of the jth metal in the short-run. $h_{j}(t-1)$ denotes the past conditional volatility dependency. D03 is the geopolitical dummy for the 2003 Iraq war. Each column represents an equation. ARMA $(1,1)$ is the most common suitable specification for model convergence and parameter statistical significance $\operatorname{ARMA}(1,1)$ is typically superior to $\operatorname{AR}(1)$, while $\operatorname{ARMA}(p, q), p>1, q>1$, is usually not much different from $\operatorname{ARMA}(1,1)$. In our case, $\operatorname{ARMA}(1,1)$ 
gives the best fit. 
Table 4: Model II-Estimates of VARMA-GARCH for Precious Metals and Exchange Rate

\begin{tabular}{|c|c|c|c|c|c|c|c|}
\hline & Gold & & Silver & & Platinum & & ER \\
\hline & \multicolumn{7}{|c|}{ Mean Equation } \\
\hline$C$ & -0.0001 & & -0.0006 & a & $-3.2 \mathrm{E}-05$ & & -0.0001 \\
\hline$A R(1)$ & 0.5711 & a & -0.1776 & a & -0.0404 & $\mathrm{~b}$ & -0.0420 \\
\hline D03 & 0.0004 & a & 0.0015 & a & 0.0006 & $\mathrm{~b}$ & 0.0004 \\
\hline $\operatorname{DFFR}(1)$ & 0.0004 & & -0.0047 & $\mathrm{a}$ & 0.0010 & & -0.0009 \\
\hline \multirow[t]{2}{*}{$M A(1)$} & -0.5474 & a & 0.0351 & & -0.0154 & & 0.0052 \\
\hline & \multicolumn{7}{|c|}{ Variance Equation } \\
\hline$C$ & $-5.0 \mathrm{E}-06$ & a & $-3.0 \mathrm{E}-06$ & a & \multicolumn{2}{|l|}{0.0000} & 0.0000 \\
\hline$\varepsilon_{\text {gold }}^{2}(\mathrm{t}-1)$ & 0.1355 & a & 0.0356 & $\mathrm{a}$ & -0.0035 & a & -0.0059 \\
\hline$\varepsilon_{\text {silver }}^{2}(\mathrm{t}-1)$ & -0.0078 & a & 0.0217 & $\mathrm{a}$ & 0.0052 & a & $-3.3 E-05$ \\
\hline$\varepsilon_{\text {platinum }}^{2}(\mathrm{t}-1)$ & 0.0255 & $\mathrm{a}$ & 0.0239 & a & 0.0695 & a & 0.0004 \\
\hline$\varepsilon_{\mathrm{ER}}^{2}(\mathrm{t}-1)$ & -0.1017 & a & -0.0508 & a & -0.1060 & $\mathrm{a}$ & 0.0032 \\
\hline$h_{\text {gold }}(\mathrm{t}-1)$ & 0.5597 & a & -0.1693 & a & 0.1318 & a & 0.0144 \\
\hline$h_{\text {silver }}(\mathrm{t}-1)$ & 0.1490 & a & 0.9530 & a & -0.0718 & a & -0.0067 \\
\hline$h_{\text {platium }}(\mathrm{t}-1)$ & 0.1529 & a & 0.0106 & a & 0.8802 & $\mathrm{a}$ & -0.0168 \\
\hline$h_{\mathrm{ER}}(\mathrm{t}-1)$ & 0.8688 & a & 0.5279 & $\mathrm{a}$ & 0.5477 & $\mathrm{a}$ & 1.0029 \\
\hline$\alpha+\beta$ & 0.695 & & 0.975 & & 0.949 & & 1.005 \\
\hline D03 & 5.0E-06 & a & 4.0E-06 & a & 0.0000 & a & 0.0000 \\
\hline $\operatorname{DFFRSQ(1)}$ & 3.3E-05 & $\mathrm{a}$ & $2.0 \mathrm{E}-06$ & & $1.4 \mathrm{E}-05$ & $\mathrm{a}$ & $-2.0 \mathrm{E}-06$ \\
\hline & & Con & nt Correlati & $n \mathrm{n}$ & trix & & \\
\hline Gold & 1.00 & & & & & & \\
\hline Silver & 0.42 & a & 1.00 & & & & \\
\hline Platinum & 0.38 & a & 0.35 & a & 1.00 & & \\
\hline$E R$ & 0.34 & a & 0.30 & a & 0.21 & $\mathrm{a}$ & 1.00 \\
\hline Log Likelihood & 30392.58 & & & & & & \\
\hline AIC & -26.32 & & & & & & \\
\hline $\begin{array}{l}\text { J.B. Stat } \\
\text { Breusch-Godfrey }\end{array}$ & 3435.79 & a & 24236.67 & a & 2440.77 & $\mathrm{a}$ & 111.38 \\
\hline $\begin{array}{l}\text { LM Stat } \\
\text { Durbin-Watson }\end{array}$ & 1.48 & & 27.32 & a & 2.10 & & 3.69 \\
\hline Stat & 2.05 & & 1.78 & & 1.94 & & 1.92 \\
\hline \#Obs. & 2304 & & & & & & \\
\hline
\end{tabular}

Notes: This model includes gold, silver, platinum and the exchange rate as the endogenous variables and $D L F F R$ and $D 03$ as the exogenous variables. ${ }^{a} a n d^{b}$ denote rejection of the hypothesis at the $1 \%$ and $5 \%$ levels, respectively. $h_{e r}(t-1)$ is the volatility proxy for the exchange rate defined as the lagged squared sum of deviation from the mean. DLFFR is logarithmic difference for the federal funds policy variable. $\operatorname{ARMA}(1,1)$ is the most common suitable 
specification for model convergence and parameter statistical significance. 
Table 5: Model III-Estimates of VARMA-DCC for the Four Metals

\begin{tabular}{|c|c|c|c|c|c|c|c|c|}
\hline & Gold & & Silver & & Platinum & & Palladium & \\
\hline & \multicolumn{8}{|c|}{ Mean Equation } \\
\hline$C$ & -0.0001 & \multirow[b]{2}{*}{$\mathrm{a}$} & -0.0006 & $\mathrm{~b}$ & 0.0005 & \multirow[b]{2}{*}{$\mathrm{b}$} & 0.0001 & \\
\hline$A R(1)$ & 0.6319 & & -0.1869 & $\mathrm{a}$ & -0.0392 & & 0.0128 & \\
\hline D03 & 0.0003 & & 0.0014 & a & 0.0002 & & 0.0002 & \\
\hline \multirow[t]{2}{*}{$M A(1)$} & -0.6083 & a & 0.0357 & & -0.0145 & & -0.0163 & \\
\hline & \multicolumn{8}{|c|}{ Variance Equation } \\
\hline$C$ & 7.0E-06 & a & 3.0E-06 & $\mathrm{b}$ & $6.0 \mathrm{E}-06$ & a & $1.8 \mathrm{E}-05$ & a \\
\hline$\varepsilon^{2}(\mathrm{t}-1)$ & 0.1337 & a & 0.0678 & $\mathrm{a}$ & 0.0899 & a & 0.1088 & a \\
\hline$h(\mathrm{t}-1)$ & 0.7790 & a & 0.9119 & a & 0.8885 & a & 0.8651 & a \\
\hline$\alpha+\beta$ & 0.913 & & 0.980 & & 0.978 & & 0.975 & \\
\hline \multirow[t]{2}{*}{ D03 } & $2.0 \mathrm{E}-06$ & b & 6.0E-06 & a & $-3.0 \mathrm{E}-06$ & a & $-8.0 \mathrm{E}-06$ & a \\
\hline & \multicolumn{8}{|c|}{ DCC Coefficients } \\
\hline$\theta_{1}$ & $0.0085^{\mathrm{a}}$ & & & & & & & \\
\hline$\theta_{2}$ & $0.9900^{\mathrm{a}}$ & & & & & & & \\
\hline $\log L$ & 27760.2781 & & & & & & & \\
\hline AIC & -24.07 & & & & & & & \\
\hline $\begin{array}{l}\text { J.B. Stat } \\
\text { Breusch-Godfrey }\end{array}$ & 3427.05 & a & 23745.84 & a & 2437.24 & a & 1447.05 & a \\
\hline $\begin{array}{l}\text { LM Stat } \\
\text { Durbin-Watson }\end{array}$ & 1.51 & & 33.45 & a & 1.83 & & 9.98 & $\mathrm{~b}$ \\
\hline Stat & 2.05 & & 1.76 & & 1.94 & & 1.87 & \\
\hline \#Obs. & 2304 & & & & & & & \\
\hline
\end{tabular}

Notes: This DCC model includes the four precious metals -gold, silver, platinum and palladium-as the endogenous variables and $D 03$ as the exogenous variable. ${ }^{a}$ and ${ }^{b}$ denote rejection of the hypothesis at the $1 \%$ and $5 \%$ levels, respectively. $\varepsilon_{j}^{2}(t-1)$ represents the past shock of the jth metal in the short-run or is news. $h_{j}(t-1)$ denotes the past conditional volatility dependency. $\theta_{1}$ and $\theta_{2}$ are the DCC parameters. D03 is the dummy for the 2003 Iraq war. Each column represents an equation. ARMA(1,1) is the most common suitable specification for model convergence and parameter statistical significance. 
Table 6: Model IV-Estimates of VARMA-DCC for Metals and Exchange Rate

\begin{tabular}{|c|c|c|c|c|c|c|c|c|}
\hline & Gold & & Silver & & Platinum & & ER & \\
\hline & \multicolumn{8}{|c|}{ Mean Equation } \\
\hline$C$ & -0.0002 & & -0.0006 & b & 0.0003 & & -0.0001 & \\
\hline$A R(1)$ & -0.9350 & a & -0.1790 & a & -0.0368 & c & -0.0524 & a \\
\hline D03 & 0.0017 & $\mathrm{a}$ & 0.0016 & a & 0.0004 & & 0.0004 & c \\
\hline $\operatorname{DFFR}(1)$ & -0.0017 & $\mathrm{~b}$ & -0.0053 & $\mathrm{~b}$ & 0.0003 & & -0.0008 & \\
\hline \multirow[t]{2}{*}{$M A(1)$} & 0.9427 & $\mathrm{a}$ & 0.0172 & & -0.0235 & & 0.0023 & \\
\hline & \multicolumn{8}{|c|}{ Variance Equation } \\
\hline$C$ & 7.0E-06 & a & 2.0E-06 & $\mathrm{b}$ & $6.0 \mathrm{E}-06$ & a & $0.0 \mathrm{E}+00$ & \\
\hline$\varepsilon^{2}(\mathrm{t}-1)$ & 0.1587 & a & 0.0689 & a & 0.1022 & $\mathrm{a}$ & 0.0171 & a \\
\hline$h(\mathrm{t}-1)$ & 0.7409 & a & 0.9090 & a & 0.8739 & $\mathrm{a}$ & 0.9806 & a \\
\hline$\alpha+\beta$ & 0.9996 & & 0.9779 & & 0.9761 & & 0.9977 & \\
\hline D03 & 4.0E-06 & a & $6.0 \mathrm{E}-06$ & a & $-3.0 \mathrm{E}-06$ & a & $0.0 \mathrm{E}+00$ & \\
\hline \multirow[t]{2}{*}{ DFFRSQ(1) } & 2.3E-05 & $\mathrm{b}$ & $4.0 \mathrm{E}-05$ & $\mathrm{~b}$ & 2.2E-05 & & 2.0E-06 & \\
\hline & \multicolumn{8}{|c|}{ DCC Coefficients } \\
\hline$\theta_{1}$ & $0.0090^{\mathrm{a}}$ & & & & & & & \\
\hline$\theta_{2}$ & $0.9892^{\mathrm{a}}$ & & & & & & & \\
\hline LogL & 30425.3657 & & & & & & & \\
\hline AIC & -26.37 & & & & & & & \\
\hline $\begin{array}{l}\text { J.B. Stat } \\
\text { Breusch-Godfrey }\end{array}$ & 3542.16 & a & 24232.16 & a & 2425.46 & a & 112.46 & a \\
\hline $\begin{array}{l}\text { LM Stat } \\
\text { Durbin-Watson }\end{array}$ & 0.13 & & 30.07 & a & 1.82 & & 6.25 & $\mathrm{~b}$ \\
\hline Stat & 2.01 & & 1.77 & & 1.94 & & 1.89 & \\
\hline Obs. & 2304 & & 2304 & & 2304 & & 2304 & \\
\hline
\end{tabular}

Notes: This DCC model includes gold, silver, platinum and the exchange rate as the endogenous variables, and DLFFR and D03 as the exogenous variables. ${ }^{a}$ and ${ }^{b}$ denote rejection of the hypothesis at the $1 \%$ and $5 \%$ respectively. $\varepsilon_{j}^{2}(t-1)$ represents the past shock of the jth metal in the short-run or is news. $\mathrm{h}_{\mathrm{j}}(\mathrm{t}-1)$ denotes the past conditional volatility dependency. $\theta_{l}$ and $\theta_{2}$ are the DCC parameters. D03 is the dummy for the 2003 Iraq war. Each column represents an equation. $\operatorname{ARMA}(1,1)$ is the most common suitable specification for model convergence and parameter statistical significance.

model convergence and parameter statistical significance. 
Table 7: Hedge Ratios and Optimal Portfolio Weights Based on Model I (VARMA)

\begin{tabular}{lcc}
\hline \multicolumn{1}{c}{ Portfolio } & Average $w_{12, t}$ & Average $\beta_{t}$ \\
\hline Gold/Silver & 0.81 & 0.29 \\
Gold/Platinum & 0.69 & 0.30 \\
Gold/Palladium & 0.87 & 0.13 \\
Silver/Platinum & 0.40 & 0.46 \\
Silver/Palladium & 0.66 & 0.24 \\
Platinum/Palladium & 0.83 & 0.32
\end{tabular}

Notes: This VARMA-GARCH model includes gold, silver, platinum and palladium as the exogenous variables, and $D 03$ as the geopolitical dummy. $w_{12, t}$ is the portfolio weight of two assets holdings at time $t$ and average $\beta_{t}$ is the risk-minimizing hedge ratio for two precious metals. 
Table 8: Hedge Ratios and Optimal Portfolio Weights Based on Model II (VARMA-GARCH) for Three Metals and Exchange Rate

\begin{tabular}{lcc}
\hline \multicolumn{1}{c}{ Portfolio } & Average $w_{12, t}$ & Average $\beta_{t}$ \\
\hline Gold/Silver & 0.80 & 0.28 \\
Gold/Platinum & 0.69 & 0.30 \\
Gold/ER & 0.23 & 0.56 \\
Silver/Platinum & 0.40 & 0.46 \\
Silver/ER & 0.10 & 0.82 \\
Platinum/ER & 0.14 & 0.47 \\
\hline
\end{tabular}

Notes: This VARMA-GARCH model includes gold, silver, platinum and the exchange rate as the endogenous variables and DLFFR and DO3 as the exogenous variables. $w_{12, t}$ is the portfolio weight of two assets holdings at time $t$ and average $\beta_{t}$ is the risk- minimizing hedge ratio for two precious metals. 
Figure 1: Paths of Daily Prices of the four Precious Metals, Federal Funds Rate and Exchange rate
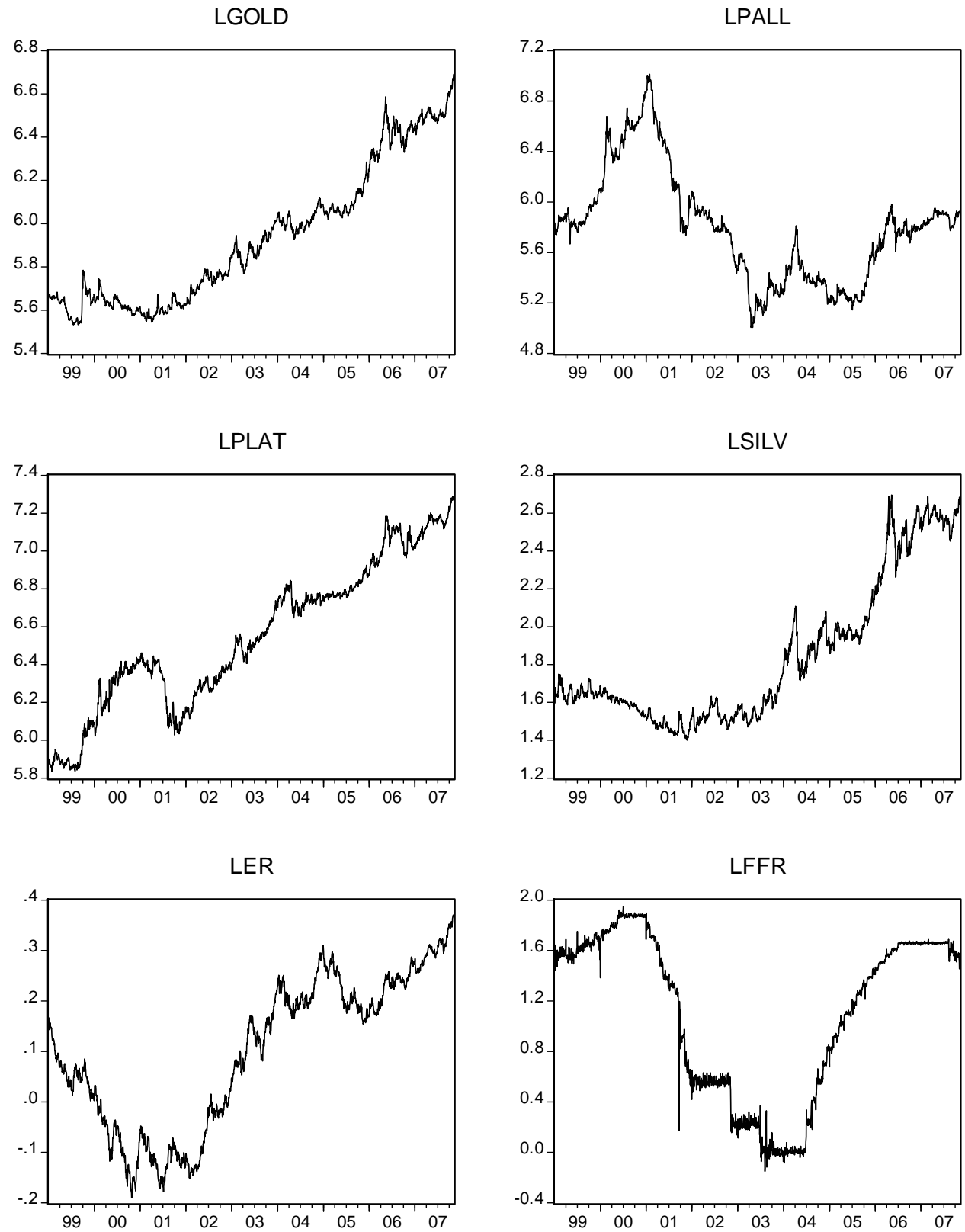

Note: All variables are expressed in logarithmic form. 
Figure 2: Estimated Dynamic Correlation Based on Model III (VARMA-DCC)

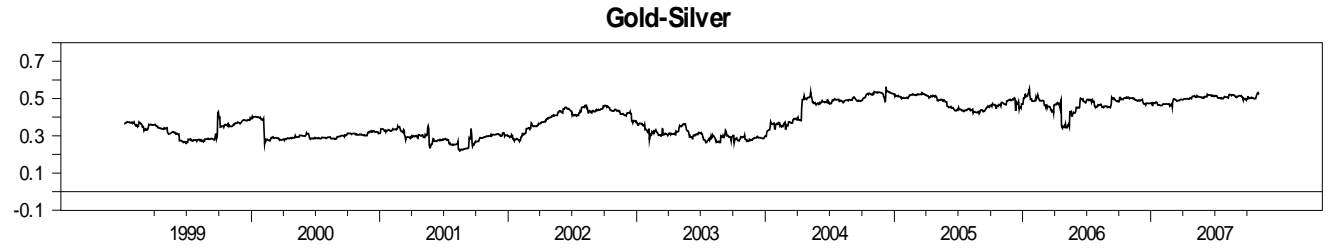

Gold-Platinum
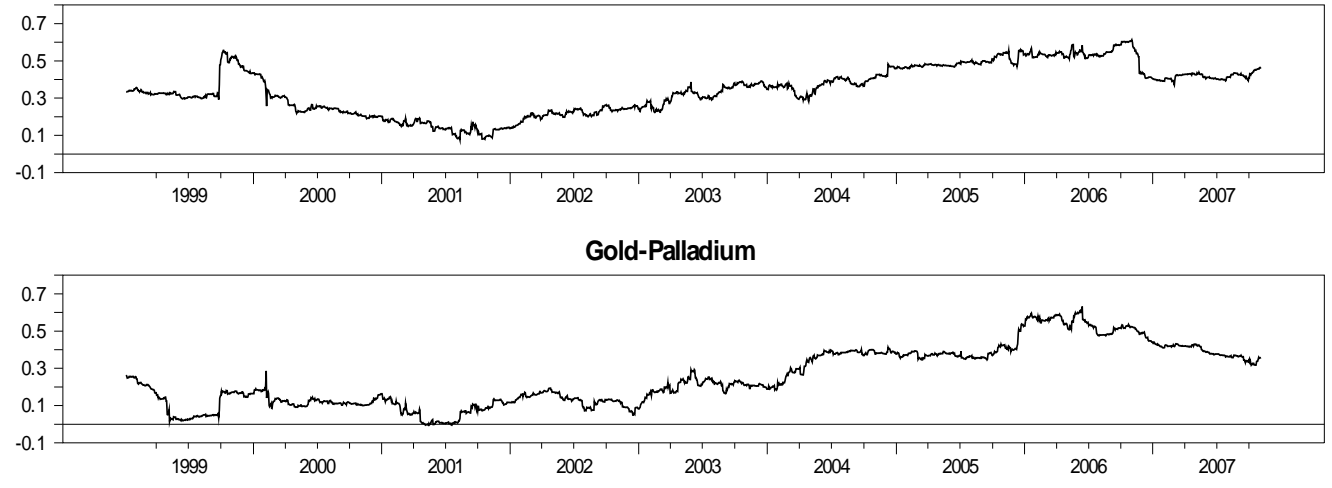

Silver-Platinum

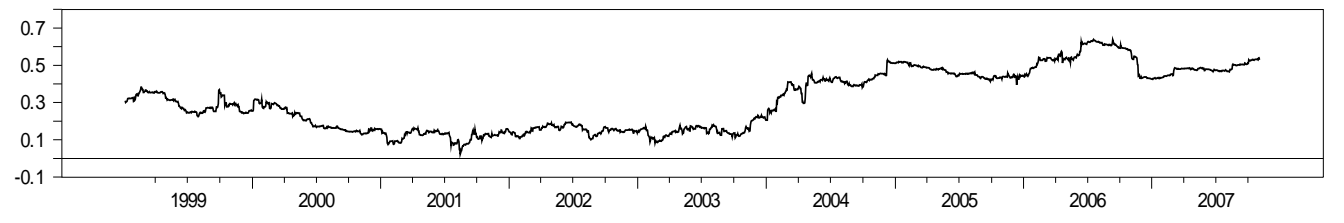

Silver-Palladium

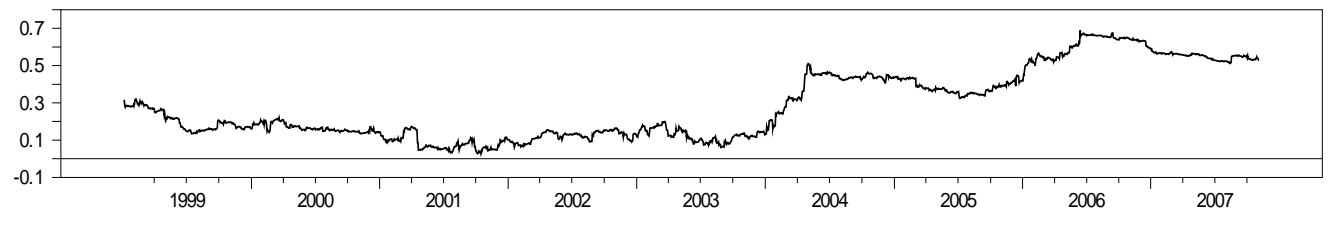

Platinum-Palladium

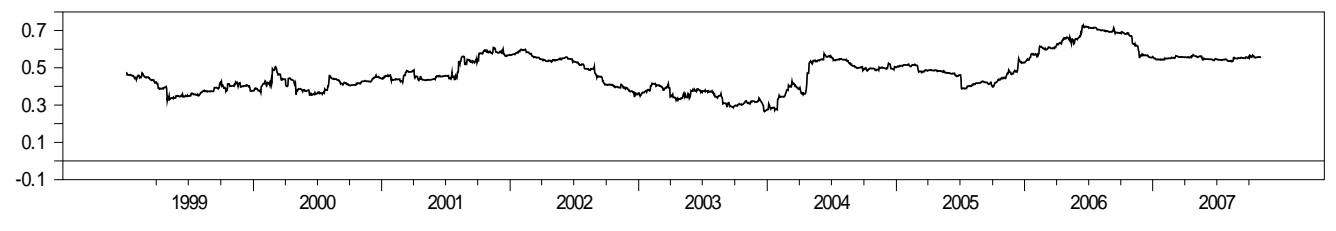




\section{References}

Adrangi, B and Chatrath, A. 2003. The dynamics of palladium and platinum prices. Computational Economics 17, 179-197.

Batten, J.M. and Lucey, B.M. 2007. Volatility in the Gold Futures Market. Discussion Paper \# 225, Institute for International Integration Studies.

Bollerslev, T. 1986. Generalized autoregressive conditional heteroskedasticity. Journal of Econometrics 31, 307-327.

Chan, F., Lim, C. and McAleer, M. 2005. Modelling multivariate international tourism demand and volatility. Tourism Management 26, 459-471.

Caporin, M. and McAleer, M. 2009. Do we really need both BEKK and DCC? A tale of two covariance models, available at SSRN: $\underline{\text { http://ssrn.com/abstract=1338190 }}$

Conrad, C. and Karanasos, M. 2009. Negative volatility spillovers in the unrestricted ECCC-GARCH model. Econometric Theory (forthcoming).

Engle, R.F. 2002. Dynamic conditional correlation: A simple class of multivariate generalized autoregressive conditional heteroskedasticity models. Journal of Business and Economic Statistics 20, 339-350.

Engle, R.F. and Kroner, K.F. 1995. Multivariate simultaneous generalized ARCH. Econometric Theory 11, 122-150.

Garman, M.B., and Klass, M.J. 1980. On the estimation of security price volatility from historical data. Journal of Business 53, 67-78.

Hamilton, A. 2009. Silver/Gold Ratio Reversion 2. 321 gold.com (June 19) http://www.321gold.com/editorials/hamilton/hamilton061909.html

Hamilton, A. 2000. Gold going platinum. ZEAL Speculation and Investment (July 7).

Hammoudeh, S. and Yuan, Y. 2008. Metal volatility in presence of oil and interest rate shocks. Energy Economics 30, 606-620.

Hassan, H. and Malik, F. 2007. Multivariate GARCH model of sector volatility transmission,” Quarterly Review of Economics and Finance 47, 470-480.

Jeantheau, T. 1998. "Strong Consistency of Estimators for Multivariate ARCH Models,” Econometric Theory 14, 70-86.

Kroner, K.F. and Ng, V.K. 1998. Modeling asymmetric movements of asset prices. Review of Financial Studies 11, 871-844.

Kroner, K.F. and Sultan, J. 1993. Time dynamic varying distributions and dynamic hedging with foreign currency futures. Journal of Financial and Quantitative Analysis 
28, 535-551.

Kyrtsou and Labys. 2007. Detecting feedback in multivariate time series: the case of metal prices and US inflation. Physica A 377, 227-229.

Ling, S. and McAleer, M. 2003. Asymptotic theory for a vector ARMA-GARCH model. Econometric Theory 19, 278-308.

Mackenzie, M., Mitchell, H., Brooks, R., Faff, R. 2001. Power ARCH modeling of commodity futures data on the London's Metal Market. European Journal of Finance 7. 22-38.

McAleer, M. 2005. Automated inference and learning in modeling financial volatility. Econometric Theory 21, 232-261.

Plourde, A., Watkins, G.C. 1998. Crude oil prices between 1985 and 1994: how volatile in relation to other commodities?. Resource and Energy Economics 20, 245-262.

Schaeffer, P. V. 2008. edt. Commodity Modelling and Pricing: Methods for Analyzing Resourses. Willey.

Tully, E. and Lucey, B. 2007. A power GARCH examination of the gold market. Research in International Business and Finance 21, 316-325.

Watkins, C. and McAleer, M. 2008. How has the volatility in metals markets changed? Mathematics and Computers in Simulation 78, 237-249.

Westerhoff, F. and Reltz, St. 2005. Commodity price dynamics and the nonlinear market impact of technical traders: empirical evidence for the U.S. corn market. Physica A: Statistical Mechanics and its Application 349, 641-648.

Yang, S.R. and Brorsen, B.W. 1993. Non linear dynamics of daily futures prices: Conditional heteroskedasticity or chaos. Journal of Futures Markets 13, 175-191. 